Kansas State University Libraries

New Prairie Press

\title{
A NEW APPROACH TO TEACHING NATURAL RESOURCE SAMPLING
}

Kenneth M. Portier

Loukas G. Arvanitis

Daniel Brackett

Follow this and additional works at: https://newprairiepress.org/agstatconference

Part of the Agriculture Commons, and the Applied Statistics Commons

\section{(c) (1) $\Theta(9$}

This work is licensed under a Creative Commons Attribution-Noncommercial-No Derivative Works 4.0 License.

\section{Recommended Citation}

Portier, Kenneth M.; Arvanitis, Loukas G.; and Brackett, Daniel (1996). "A NEW APPROACH TO TEACHING NATURAL RESOURCE SAMPLING," Conference on Applied Statistics in Agriculture. https://doi.org/ $10.4148 / 2475-7772.1323$

This is brought to you for free and open access by the Conferences at New Prairie Press. It has been accepted for inclusion in Conference on Applied Statistics in Agriculture by an authorized administrator of New Prairie Press. For more information, please contact cads@k-state.edu. 


\title{
A NEW APPROACH TO TEACHING NATURAL RESOURCE SAMPLING
}

\author{
Kenneth M. Portier' Loukas G. Arvanitis', Daniel Brackett ${ }^{2}$ \\ ${ }^{1}$ Department of Statistics and ${ }^{2}$ School of Forest Resources and Conservation, \\ University of Florida, Gainesville, FL 32611-0339
}

\begin{abstract}
A basic undergraduate course in statistics is often not adequate for students in renewable natural resource programs such as wildlife, forestry, fisheries, and related subjects. A strong foundation in the basics of sampling in time and space of forest, vegetation, wildlife and fish populations is needed. A brief account of our experience in teaching such a course over the last three years along with progress on developing course-related material and activities is reported. This includes the development of: 1) computer-based simulations; 2) in-class participation simulations to illustrate the basic concepts of sampling in space and time; 3) exercises to introduce students to basic field sampling methods (quadrat, line and point sample units, mark/recapture, radio telemetry, etc.); and 4) an associated hypermedia text. From the beginning, emphasis is placed on cost-effectiveness and on the importance of sampling in the decision-making process. Students are required to develop their own sampling project, implement the project, present the results in an open forum, and prepare an associated report in the format of a scientific paper.
\end{abstract}

Keywords: Multimedia, simulations

\section{Introduction}

It is generally agreed that only one undergraduate course in statistics is not adequate to address the needs of most science undergraduate majors. For students pursuing studies in traditional natural resource science programs such as forestry, wildlife, fisheries, botany, zoology, as well as the more recent and popular programs in natural resource conservation, environmental, soil and water sciences, a second, applied statistics course can clarify concepts and methods from the first course while demonstrating the usefulness of basic statistical methods in understanding natural systems. Traditionally, a first course in statistics is taken in the first two years of college. It covers topics such as introductory probability, simple random sampling, continuous and discrete distributions, mean and variance estimation, the standard error of the mean, construction of confidence intervals, and simple one and two sample mean comparison tests. Students studying the natural resources need to go beyond these basic concepts and gain an understanding of why and how one samples natural resource populations, how space and time are accommodated in both the study design as well as data analysis, and how statistics are used to facilitate management and conservation decisions. In this paper we discuss a natural resource sampling course, offered at the beginning of the junior year, which attempts to satisfy these needs. First, we establish the general knowledge base of students entering the course. 
In general, at the beginning of their junior year, forestry, wildlife and natural resource students are just beginning to take the core course work for their respective majors. Their knowledge of plant and wildife ecology, forestry, and ecosystems is relatively superficial at this point. The average student has not been exposed to research study design concepts, approaches to measurement and data analysis or how to use these to support resource management decisions. Most students have had an introduction to basic microcomputer applications, but even by their junior year have not had to actually use these applications to manipulate data or produce analyses and reports.

The typical undergraduate forestry major takes a course in forest inventory methods at the beginning of their junior year. This is essentially a sampling course which concentrates on sampling design components (stratification, systematic, multi-stage, multi-phase) and forest biometry methods. This course is followed up with a forest mensuration course, which includes significant field work emphasizing traditional methods of estimating forest yields. Zoology, botany and wildlife juniors, often take a general ecology course, which may include basic vegetation and animal sampling techniques. Field exercises stress specific measurement techniques - quadrat, line, transect sampling - often without placing them in the context of an overall study design. The standard approach in each of these courses is to discuss only estimation of population parameters, with little or no discussion of confidence intervals or associated statistical inference.

\section{Course Content}

The objectives of our natural resource sampling course are to: 1) review basic statistical estimation and inference concepts in the context of sampling natural systems; 2) aid the student in identifying natural resource population parameters necessary to making management and resource decisions; and 3 ) introduce and develop sampling study designs and measurement techniques which provide cost-effective and statistically efficient estimates of these population parameters along with confidence statements. At the end of the course, students should be able to state study design objectives, identify key parameters, choose appropriate measurement and estimation techniques, implement the study and report the results. In addition, they must show how their study supports sound resource management decisions.

\subsection{Basic Questions}

For a successful sampling study design, students are taught that there are five basic questions to be answered before any field work is undertaken: What are the sampling study objectives? What are the population parameters of interest? What resources are available(time, money, personnel, equipment, etc.)? What is the sampling unit?, How will sampling units be selected?, and How will raw data be processed to produce parameter estimates and confidence intervals? 


\section{What are the sampling study objectives?}

We review with students the basic objective of natural resource sampling studies: identifying and estimating the unknown population parameters (density, abundance, biomass, association, etc) necessary to making decisions and assessing impact. Emphasis is placed on the importance of having written objectives prior to any detailed discussion of sampling design. Case study discussions and guest lecturers all emphasize study objective definition.

\section{What are the population parameters of interest?}

Natural resource students are familiar with populations, such as natural and man-made forests, shrub and herbaceous vegetation, terrestrial and aquatic animals, and microbiota. They are less likely to consider the physical environment, such as ground water, soil chemistry, etc. as a population. In introductory statistics classes, the only types of population measurements (random variables) considered are amounts, such as age, height, weight, area, and characterization categories such as gender, color or health condition. The population parameter of primary interest is the mean amount or proportion. For natural resource studies, the population parameter of interest is often a total, if the population can be considered finite (geographically and temporally bounded), or a density, (average per unit area) if the population is unbounded. Getting the right measurements to estimate these parameters is much more difficult than getting data for estimating a mean or proportion.

Other parameters of interest include 1) indices of spatial or temporal pattern, 2) indices of diversity of the population, and 3) survival. All of these parameters are difficult to estimate because their definitions require specification of spatial and temporal bounds. Comparisons of these parameters over time and space among different management "treatments" is what constitutes environmental impact assessment.

Finally, even the definition of what are the basic elements of the population must be clarified. Wildlife populations may consists of separate individuals or ill-defined groups. Vegetation may be defined by individuals (say, trees) having little true area compared to the total population area, or by a patch, which covers a significant fraction of the total study area. A continuous surface or volume on the other hand has no natural basic element; basic elements for such populations are defined by the physical device used to sample it.

\section{What is the sampling unit?}

In natural resource sampling, the sampling unit may be natural, such as an individual tree, bird or vegetation patch, or artificial, such as a quadrat, line or point.

For forest and vegetation sampling we use natural units, such as individuals, and artificial units, such as points, quadrats, and lines. For the artificial units, further information must be supplied before the sampling unit is fully specified. For quadrats, we must specify shape (square, 
rectangular, long thin strips, circular), area, and orientation. Lines require a length and orientation. These latter decisions have important ramifications on the characteristics of the data collected and the properties of parameter estimates.

If we wish to estimate means or proportions of animal populations, getting an acceptable sample of individuals may require artificial sampling devices, such as nets or trap arrays (conceptually similar to a quadrat). Estimating the population total or density may require such techniques as aerial or land counts of quadrats (or strip transects). Individuals may be captured, marked then released to mix with the larger population. Subsequent success in recapturing these marked individuals will provide information for total, density and/or survival parameters. Exploited (hunted and fished) populations provide other information, which may be used to estimate population size. Radio telemetry can be used to determine how much and what parts of the landscape is used by individuals.

The non-biotic components of the environment can only be sampled using artificial sample units. These units are usually quadrats, such as soil cores or water samples, which have insignificant area or volume compared to the total population. Less often the sample units are larger areas/volumes or even lines (e.g. soil radar or sonar profiles of lake bottoms).

It is important that students are able to identify each of these sampling units and recognize the measurement (random variable) provided by each unit. The measurement is either a count (as with quadrat or line techniques) or an amount (e.g. length of line segment crossing a vegetation patch). The concept of replication of sample units is much easier to understand if the student first has a clear definition of the sample unit.

\section{How will sampling units be selected?}

The answer to this question can be found in any number of statistical sampling texts. Natural resource students must learn about 1) simple random selection, 2) stratification, 3) systematic selection and in particular spatial sampling grids, 4) cluster and multi-stage selection, and 5) multiphase (ratio) methods.

\section{How will raw data be processed to produce parameter estimates and confidence intervals?}

The quality of parameter estimates is only as good as the data used to compute them and the estimating equations used. Students are encouraged to design forms for data collection and engage in continuous examination of incoming data for obvious errors. While most of the estimating equations are straight-forward, we attempt in each case to motivate how the estimator was developed. In addition, each estimator used is presented with an associated confidence interval. 


\section{What other information will be collected?}

We stress the importance of using covariables, to increase the precision of the parameter estimates at only minimal increase in implementation cost. Since the most expensive phase of sampling is the field work to collect the data, the collection of multiple variables (say tree height, diameter, radial growth, etc) at each sample unit does not substantially increase cost, but can significantly increase the information, thus making the design cost-effective.

\subsection{Related topics}

\section{Manipulative versus Mensurative Study Design}

Students intuitively understand that real knowledge and understanding of natural systems comes not just from estimating population parameters, but from comparing these estimates among critical populations. What they do not often appreciate are the rules for performing correct and effective comparisons. Students need to understand the difference between a manipulative experiment, where the researcher has some measure of control and the ability to apply a "treatment", and a mensurative experiment (a sampling study with a comparative component) in which the researcher has little if any control and usually no "treatment" is applied. The differences between the two classes of study designs usually shows up in discussion of the difference/similarity between a sample unit (sample study) and a replicate (experimental unit), or between a stratum (used to improve the estimate of the population parameter of interest) and a block (used to improve comparisons among treatments and/or increase the scope of the study). In addition, while homogeneity of variance might be reasonably expected to hold in a manipulative experiment, no such expectation would hold for a mensurative experiment.

\section{Geographic Information Systems and Spatial Scale}

The advent of geographical information systems and other visualization tools for spatial examination of ecosystems has changed the type of questions and approaches to many resource management problems. Associated with these technologies are numerous issues related to measurement and spatial scale. In a course on natural resource sampling, it is important that students be exposed to these issues and understand how the statistical sampling tools facilitate better visualization. Development of spatial correlation models and analysis of spatial patterns and data is beyond the scope of this entry level course. We address instead how the combination of spatial pattern (random, regular, or aggregated) and quadrat size, for instance, impact the precision of the resulting density estimate. Aggregated and regular spatial patterns are defined in terms of increased or decreased probability of finding a neighboring point within a fixed diameter circle as compared to a random (Poisson point) process. 


\section{Course Format}

We have found a combination of: 1) traditional lectures aided by multimedia, 2) in-class manual and computer-generated simulations, 3) in-lab computer simulations and exercises, 4) field exercises, 5) homework, and 6) hands-on projects and presentations provides an effective learning experience. Our experiences in teaching natural resource sampling over the last three years suggest a more active approach to teaching sampling will produce excellent results.

\subsection{Traditional Lectures}

The traditional lecture, the standard approach to teaching statistics, is least enjoyed by the students. We use lectures to introduce the limited mathematical notation necessary to developing parameter estimates and their associated confidence intervals. It is very important to maintain a consistent mathematical notation, since changes in notation only confuse the student

Traditional lectures open support discussion of homework and other worked examples, and the instructor to work through complex case studies. We recommend that three to four detailed case studies be introduced early on in the course. Each case study should represent areas with significant and unresolved ecosystem management and conservation issues. In addition, case studies should have active research involvement by numerous research groups, and be close enough to the university that students can visit the area. We have found that many students, if properly motivated, will take day trips to the case study areas. While our university has two ready-made case studies in the university research forest $(2,043$ acres) and the university research wildlife management preserve (3,000 acres), students have preferred case studies which are less academic, such as city greenways, nature parks and state preservation lands (nature areas)

Periodically, we invite faculty, graduate students, or professionals actively involved with natural resource studies to give fifteen minute presentations to the class (usually slide, video or multimedia). Presenters are requested to emphasize the design and measurement concerns relating to their research or management objectives. An additional fifteen minutes is allocated to answering student questions, of which there are usually many. As would be expected, at least half of the questions involve non-statistical aspects of the study, but with proper warning, presenters can often direct the discussion onto the more statistical topics. This approach assists students in relating classroom presentations to real-world problems. Students get a feel for sampling and estimation needs and concerns in current, active research, and presenters get a first look at potential future assistants and students. This first contact has lead to a number of summer intern positions for the students and satisfied employers.

Multimedia adds an important new element to the traditional classroom lecture. Taking a computer, video recorder, and projection system into the classroom allows the instructor to use interactive programs to visualize basic concepts and computations. A favorite but simple example of this is the development of a spreadsheet program to compute an estimate from a complicated estimator (say the variance of the overall mean in stratified sampling) in front of the class. 


\subsection{In-Class Simulations}

We have found, as have many before us, that properly designed in-class simulations are more effective in getting students to grasp various basic concepts (such as the sampling distribution of an estimator and the nature of a confidence interval) than simple lecturing. For some topics, such as the effect of size and shape of quadrats on the statistical properties of final estimates, simulation is the most convincing approach to comprehending basic concepts and ideas. In-class simulations as well as simulations for homework allow students to practice generating random samples in space as well as practice computing and comparing estimates.

Where possible, we use standard computer spreadsheet programs to generate the computer based simulations. Students are encouraged in homework problems to repeat similar simulations. The authors, with programmer support, have developed and use a set of spatial sampling simulation module using LispStat (Tierney, 1990). This module explores quadrat and line transect sampling issues related to sample size, quadrat size, quadrat shape and spatial point pattern effects on the final estimates.

\subsection{In-Lab Computer Exercises}

The same simulation applications (LispStat and spreadsheet) used in the classroom are available in the computer lab for students to use. The importance of basic concepts is reasserted by having the students do their own simulations in the lab and report the results. Students are also taught the benefits of playing the simulation "what if" game to examine alternate study designs. Since the need to perform hand calculations is minimized, students can and do attempt more complex designs. We have also incorporated an introduction to GIS and analysis of landscape level issues into another lab.

\subsection{Field Exercises}

Students pursue natural resource programs because of their intense interest in natural systems. Keeping them interested in sampling requires that they practice the methods under field conditions. We require students to participate in four Saturday morning workshops from a list of topics which include aerial photo interpretation, vegetation sampling, trapping and marking animals, radio telemetry, fish sampling, and forest mensuration techniques. In addition, students can receive credit for field experience if they volunteer to help with sampling on a faculty or graduate student research project, or a sampling project run by the county natural resource manager. Students have needed little encouragement to seek outside projects. 


\subsection{Homework}

In developing homework problems, we present the student with more detail than usually found in statistics problems sets. Our goal is to get the student interested in both the problem and the data analysis. We present a study objective and provide some background on the problem. Data is then presented along with a numbered list of analyses (computations) and questions, which must be answered. Computations follow directly from the in-class examples and course notes.

Students are expected to write short reports interpreting the results of their analysis. Some reports are graded on both form and content. Our success in getting students to write more than a one line interpretation of the results has been limited. Students are just not convinced that we want discussion beyond simply the estimate and its confidence interval. We continue to explore alternative ways of supporting this activity.

\subsection{Major Project and Presentation}

In lieu of a final exam, students must propose, implement and report the results of their own sampling project. Students form teams of two or three individuals, which then propose, formally and in writing, a sampling project, which has as its goal the estimation of a population parameter of interest. A pre-proposal is first reviewed by the instructors before a formal proposal is presented. Actual study implementation time varies from one to several days. The data collected is analyzed and results written-up in scientific paper format. Each team prepares a poster of their methods and results and presents it before class members, faculty and other guests during an outdoor special session during the last week of classes.

Using the assistance of other faculty, students and guests, the instructors grade both papers and posters for form and content, which together constitute the final grade. Poorly constructed papers and posters may be redone if the students desire. In recent years we have used prototype papers and posters to demonstrate the type of final product necessary for a passing mark. When presented in this manner, the final reports and posters are rarely disappointing, although many reports are sent back for extensive revisions.

Students enjoy presenting their projects to their peers and to other faculty. They also benefit from the review their projects get from their classmates. While we feel that the project experience is a beneficial one, often the most important lesson learned is the importance of choosing good, hardworking team members. 


\section{Future Directions}

The most difficult part of teaching natural resource sampling is the lack of a suitable textbook. None of the books we examined met our expectations for presenting the material as described in a logical and clear manner. In the third presentation of the course, we used our own notes.

In the next presentation of the course, we will be experimenting with the use of the World Wide Web to provide students access to the course materials. Rather than simply presenting the class notes to the students, we are attempting to create a hypermedia textbook. Students will be required to review assigned material prior to class sessions, allowing more classroom time for discussions, clarifications and individual and team projects.

Our goal is to create a reference tool which, while useful for the natural resource sampling course, will also be valuable to future professionals. The text is organized around answers to the five basic questions, with hyperlinks allowing quick and logical connections between sample units, sample selection, and estimation techniques. While the document is nowhere near complete, it can be viewed by going to the University of Florida School of Forest Resources and Conservation home page (http:/Www.sfrc.ufl.edu/) and proceeding through 'Classes' to the Natural Resource Sampling course page then onto the 'Prototype Hyper Textbook'.

Publishing in the Internet adds something that neither traditional publishing nor broadcasting provides: the potential for interaction between the author(s) and the global audience (Fry and Paul 1995). Increasingly, more students have access to WWW. They will be required to review the designated subject areas and come to class for discussion and clarifications. Ultimately, through hyperlinks, this approach will allow for a custom-made text, which will be easy to update, relatively inexpensive and most effective in meeting individual student needs.

\section{Acknowledgments}

This work has been sponsored by USDA Higher Education Program Challenge Grant 94-384110156 and by the Institute of Food and Agricultural Sciences of the University of Florida. This is UF/IFAS Agricultural Experiment Station publication R05443.

\section{Literature Cited}

Fry, A and D. Paul. 1995. Publishing on the Internet. Warner Books, N. Y.

Tierney, L. 1990. LispStat: an object-oriented environment for statistical computing and dynamic graphics. John Wiley \& Sons, N. Y. 